\title{
Contaminação microbiológica de alimentos comercializados em restaurantes de auto-serviço de Itumbiara-GO
}

\author{
Elias Jose Oliveira von Dolinger ${ }^{1}$ \\ Poliana Castro Melo ${ }^{2}$ \\ Gilsimeire Rodrigues Morais ${ }^{3}$ \\ Carlos Roberto Menezes da Silva ${ }^{3}$ \\ Denise Von Dolinger de Brito ${ }^{1 *}$ \\ ${ }^{1}$ Universidade Federal de Uberlândia, Campus Umuarama \\ Avenida Amazonas s/n bloco, $4 \mathrm{C}-2^{\circ}$ andar, Laboratório de Microbiologia \\ CEP 38400-902, Uberlândia-MG, Brasil \\ ${ }^{2}$ Universidade Estadual Paulista "Júlio de Mesquita Filho", Jaboticabal-SP, Brasil \\ ${ }^{3}$ Universidade Luterana do Brasil (ILES ULBRA), Itumbiara-GO, Brasil \\ *Autor para correspondência \\ denisebrito@terra.com.br
}

Submetido em 07/03/2010

Aceito para publicação em 14/09/2010

\section{Resumo}

O objetivo da presente pesquisa foi avaliar as condições microbiológicas de alimentos servidos em restaurantes "self-service" em Itumbiara-GO. No total, foram estudados 23 restaurantes e os alimentos coletados foram macarronada, salada de tomate e pepino, maionese e carne de panela. As amostras foram adquiridas com o apoio de fiscais da Vigilância Sanitária Municipal de Itumbiara-GO. Foram pesquisados mesófilos totais, estafilococos coagulase positivo e coliformes termotolerantes. Tanto o preparo das amostras como de suas diluições foram realizadas segundo as técnicas recomendadas pelo Compendium of Methods for the Microbiological Examination of Foods. Em apenas um restaurante não foi detectado contaminação de alimentos. Em $16(69,6 \%)$ deles houve pelo menos três tipos de alimentos contaminados com contagens acima do padrão microbiológico permitido por lei. Todos os patógenos pesquisados foram detectados em pelo menos um tipo de alimento. O patógeno mais freqüente foi o estafilococos coagulase positivo (86,5\%). Os resultados são alarmantes, havendo a presença nos alimentos de microrganismos potencialmente patogênicos, o que demonstra a baixa qualidade higiênico-sanitária durante o preparo dos alimentos pesquisados.

Unitermos: alimentos, avaliação microbiológica, restaurantes

\section{Abstract}

Microbiological contamination of food at self-service restaurants. The purpose of this study was to evaluate the microbiological conditions of food served in self-service restaurants in Itumbiara-GO. In total, we studied 23 restaurants and the foods collected were: pasta, tomato and cucumber salad, mayonnaise and meat from the pan. The samples were acquired with the support of the municipality's sanitary inspectors. Our research was focused on total mesophiles, coagulase positive staphylococci and heat tolerant coliforms. The sample preparations and their dilutions were performed according to the technique recommended by the Compendium of 
Methods for the Microbiological Examination of Foods. Non-contamination of food was confirmed in only one restaurant. In 16 restaurants (69.6\%), there were at least three types of food contaminated with scores above the standard allowed by law. All the pathogens studies were detected in at least one type of food. The most common pathogen was coagulase positive Staphylococcus (86.5\%). These results are alarming. The presence of potentially pathogenic microorganisms in the food demonstrates the poor sanitary conditions under which it was prepared.

Key words: food, microbiological analysis, restaurants

\section{Introdução}

Há um aumento cada vez maior do número de estabelecimentos públicos de alimentação. Isto se deve principalmente, ao aumento da população e, portanto, ao número de pessoas que procuram tais estabelecimentos a fim de neles fazerem suas refeições (Jacob e Powell, 2009). Pesquisas realizadas pelo Centers for Disease Control and Prevention (CDC) revelam que entre $1998 \mathrm{e}$ 2002 quase um quarto dos surtos de agentes etiológicos transmitidos por alimentos estava relacionado à residência privada, enquanto outros três quintos se originaram de restaurantes (Lynch et al., 2006). Da mesma forma, fiscalização especificamente na Inglaterra e País de Gales no período compreendido entre 1992 a 2003 comprovou que a maioria dos surtos de alimentos, servidos em estabelecimentos comerciais, foi devida a alimentos servidos em bares e restaurantes (O'Brien et al., 2006).

Entre os principais patógenos veiculados por alimentos destacam-se Salmonella, Escherichia coli e Staphylococcus aureus que são frequentemente isolados de carne, ovos, alimentos frescos e outros produtos de origem animal (Centers for Disease Control and Prevention, 2010). Isto reforça a demanda crescente da implantação de medidas eficazes que garantam a segurança alimentar, desde as etapas iniciais de produção até os processos industriais, além da manipulação direta momentos antes do consumo (Havelaar, 2010).

A ANVISA, dentro da sua competência, regulamentou em 2002 a RDC nº 275 (ANVISA, 2002) que estabelece as orientações necessárias para inspeção sanitária por meio da verificação do Sistema de Análise de Perigo e Ponto Crítico de Controle (APPCC) da empresa produtora e de serviços de alimentos e os aspectos que devem ser considerados para a aplicação de boas práticas de fabricação (BPF).
Partindo do exposto, procurou-se estudar as condições microbiológicas de alguns tipos de alimentos servidos em restaurantes tipo self-service, situados na cidade de Itumbiara-GO.

\section{Material e Métodos}

\section{Análise microbiológica - Primeira etapa}

Foram pesquisados 23 restaurantes tipo self-service da cidade de Itumbiara-GO. A coleta foi realizada na cozinha de cada estabelecimento utilizando-se recipientes estéreis, após correta higienização das mãos. Os alimentos pesquisados incluíram macarronada, salada de tomate e pepino, maionese e carne de panela, os quais foram coletados de cada restaurante. As amostras foram adquiridas com o apoio de fiscais da Vigilância Sanitária Municipal de Itumbiara-GO. Para cada alimento foram obtidas duas amostras de $25 \mathrm{~g}$, que eram mantidas sob refrigeração até o momento das análises. O tempo decorrido entre a coleta das amostras e o início dos exames nunca excedeu de $60 \mathrm{~min}$.

Realizou-se a pesquisa de mesófilos totais, estafilococos coagulase positivo e coliformes termotolerantes. Todas as amostras foram diluídas segundo as técnicas recomendadas pelo "Compendium of Methods for the Microbiological Examination of Foods" (Downes, 2001), adicionando-se 25g de cada amostra em $225 \mathrm{~mL}$ de água peptonada $0,1 \%$ e homogeneização em stomacher. Em seguida, diluição seriada em escala decimal foi realizada utilizando-se o mesmo diluente.

Aeróbios mesófilos foram enumerados por semeadura pour plate e em duplicata de diluições selecionadas em ágar padrão de contagem, com incubação a $35^{\circ} \mathrm{C}$ por $48 \mathrm{~h}$, quando as colônias formadas foram enumeradas e os resultados expressos em Unidades Formadoras de Colônias por g (UFC/g). 
Para a pesquisa de coliformes termotolerantes foi utilizado inicialmente um teste presuntivo em caldo lactosado seguido da técnica dos tubos múltiplos em caldo EC, com incubação a $45^{\circ} \mathrm{C}$ por $24 \mathrm{~h}$. Os resultados obtidos foram expressos em Número Mais Provável por $\mathrm{g}(\mathrm{NMP} / \mathrm{g})$.

Estafilococos coagulase positiva foram enumerados em Agar Baird Parker, onde diluições selecionadas foram semeadas por superfície e em duplicata, com incubação a $35-37^{\circ} \mathrm{C}$ por $48 \mathrm{~h}$. As colônias suspeitas foram inoculadas em caldo Brain Heart Infusion para posterior teste de coagulase.

\section{Ajustamento de conduta}

Após a detecção de problemas quanto a contaminação microbiológica dos alimentos acima dos padrões permitidos pela ANVISA, todos os resultados foram apresentados à vigilância Sanitária Municipal de Itumbiara-GO assim como à Promotoria da cidade que elaborou um Termo de Ajustamento de Conduta onde todos os funcionários de cada restaurante avaliado foram obrigados a participar de dois mini-cursos, oferecidos para as devidas orientações quanto à importância de exercer as boas práticas de fabricação dos alimentos, seguindo o conteúdo do Regulamento Técnico de Boas Práticas para Serviços de Alimentação, aprovado pela resolução RDC n 216 , de 15 de setembro de 2004 (ANVISA, 2004). Adicionalmente, foi realizada nova visita em cada estabelecimento, com o acompanhamento de um fiscal da vigilância sanitária, com a finalidade de orientar a cada proprietário sobre mudanças que deveriam ser realizadas na estrutura física da cozinha de forma a garantir maior segurança e qualidade na produção do alimento.

\section{Análise microbiológica - Segunda etapa}

Depois de transcorridos três meses da realização do mini-curso nova análise microbiológica dos alimentos foi realizada nas mesmas condições já descritas acima, inclusive os alimentos pesquisados e a quantidade em gramas de amostras obtidas. A única diferença para a primeira etapa foi a exclusão de três restaurantes pelo fato de terem optado pelo fechamento de suas atividades.

\section{Análise estatística}

Foi realizada análise estatística para comparação dos níveis de contaminação microbiológica do alimento entre as duas etapas do trabalho. Utilizou-se análise univariada incluindo o teste do $\chi^{2}$ e Exato de Fisher, analisados através do programa Epi Info Software versão 2000 (CDC, Atlanta).

\section{Resultados e Discussão}

Dos 23 estabelecimentos avaliados, foi observado que apenas um deles não apresentou contaminação dos alimentos acima do padrão permitido pela ANVISA. Adicionalmente, $16(69,6 \%)$ estabelecimentos apresentaram pelo menos três tipos de alimentos contaminados acima deste mesmo padrão (Tabela 1).

No total de amostras das quatro variedades de alimento, detectou-se a presença expressiva (acima de $10^{3}$ ) de estafilococos coagulase positiva na maionese de $86,9 \%$ restaurantes. Adicionalmente, em dois $(8,7 \%)$ destes estabelecimentos, houve também a contaminação da maionese por coliformes a $45^{\circ} \mathrm{C}$ (Tabela 2 ).

Aalta incidência de estafilococos coagulase positivo, presente na maionese, indica a falta de higiene durante a manipulação e preparação do alimento (Kolevska e Kocic, 2009). Estudo realizado por Pereira et al. (1994), com 55 indivíduos que manipulavam alimentos em uma cozinha industrial de Belo Horizonte-MG, mostrou que 58,2\% deles apresentavam Staphylococcus aureus, sendo que, $30,9 \%$ eram cepas enterotoxigênicas no nariz, em torno e embaixo das unhas, o que acarretou uma contaminação de $35 \%$ dos alimentos servidos. 
TABELA 1: Análise da contaminação bacteriana ocorrida nos restaurantes self-service de Itumbiara-GO, no período entre Janeiro a Dezembro de 2008.

\begin{tabular}{|c|c|c|c|c|c|c|c|c|c|c|c|c|c|c|c|c|c|c|c|c|c|c|c|}
\hline \multirow{2}{*}{$\begin{array}{l}\text { Alimentos analisados/ } \\
\text { Microrganismos detectados }\end{array}$} & \multicolumn{23}{|c|}{ Restaurantes } \\
\hline & A & $\mathrm{B}$ & $\mathrm{C}$ & $\mathrm{D}$ & $\mathrm{E}$ & $\mathrm{F}$ & $\mathrm{G}$ & $\mathrm{H}$ & I & $\mathrm{J}$ & $\mathrm{L}$ & M & $\mathrm{N}$ & $\mathrm{O}$ & $\mathrm{P}$ & Q & $\mathrm{R}$ & $\mathrm{S}$ & $\mathrm{T}$ & $\mathrm{U}$ & $\mathrm{V}$ & $\mathrm{X}$ & Z \\
\hline $\begin{array}{l}\text { Estafilococos coagulase positiva } \\
\text { na salada }\end{array}$ & & & & & & & & & + & & & + & & + & & & & & & & & & \\
\hline Coliformes na macarronada & & & & + & + & & & & & & & & & & & & & & & & & & \\
\hline Coliformes na carne de panela & & & & + & + & & & & & & & & & & & & & & & & & & \\
\hline Coliformes na maionese & & & & & & & & & & & & & & & & & + & + & & & & & \\
\hline Bactérias mesófilas na salada & & & & & & & & & & & & & & & & & & & & + & & + & + \\
\hline $\begin{array}{l}\text { Estafilococos coagulase positiva } \\
\text { na maionese }\end{array}$ & + & + & + & + & + & + & + & + & + & + & + & + & + & + & + & & + & + & + & + & + & & \\
\hline Coliformes na salada & & & & & & + & + & + & + & + & + & + & + & + & + & & + & + & + & + & + & + & + \\
\hline
\end{tabular}

O sinal + indica que houve a ocorrência do microrganismo acima do padrão microbiológico estabelecido pela RCD 12, de 02 de janeiro de 2001 da ANVISA.

TABELA 2: Ocorrência de contaminação bacteriana acima dos padrões permitidos por lei nas amostras de alimentos comercializados em 23 restaurantes de auto-serviço de Itumbiara-GO, no período entre Janeiro a Dezembro de 2008.

\begin{tabular}{|c|c|c|c|c|c|c|}
\hline \multirow[t]{2}{*}{ Alimentos } & \multicolumn{2}{|c|}{$\begin{array}{l}\text { Bactérias } \\
\text { mesófilas }\end{array}$} & \multicolumn{2}{|c|}{$\begin{array}{c}\text { Coliformes } \\
\text { termotole- } \\
\text { rantes }\end{array}$} & \multicolumn{2}{|c|}{$\begin{array}{c}\text { Estafilococos } \\
\text { coagulase } \\
\text { positivo }\end{array}$} \\
\hline & $\mathbf{N}$ & $\%$ & $\mathbf{N}$ & $\%$ & $\mathbf{N}$ & $\%$ \\
\hline Macarronada & 0 & 0 & 2 & 8,7 & 0 & 0 \\
\hline Salada & 3 & 13,0 & 17 & 73,9 & 3 & 13,0 \\
\hline Maionese & 0 & 0 & 2 & 8,7 & 20 & 86,9 \\
\hline $\begin{array}{l}\text { Carne de } \\
\text { panela }\end{array}$ & 0 & 0 & 2 & 8,7 & 0 & 0 \\
\hline $\begin{array}{l}\text { Máximo da } \\
\text { RDC } 12\end{array}$ & \multicolumn{2}{|c|}{. } & \multicolumn{2}{|c|}{$10^{2}(\mathrm{NMP} / \mathrm{g})$} & \multicolumn{2}{|c|}{$10^{3}(\mathrm{UFC} / \mathrm{g})$} \\
\hline
\end{tabular}

Em $17(73,9 \%)$ restaurantes, as amostras de salada de tomate e pepino apresentaram-se contaminadas por coliformes a $45^{\circ} \mathrm{C}\left(2 \times 10^{4} \mathrm{UFC} / \mathrm{g}\right)$ indicando que o alimento é impróprio para o consumo. Em três $(13,0 \%)$ destes foram detectadas também bactérias mesófilas e estafilococos coagulase positivo em populações acima de $3 \times 10^{4} \mathrm{UFC} / \mathrm{g}$ e $2 \times 10^{3} \mathrm{UFC} / \mathrm{g}$, respectivamente. Além disso, a contaminação por coliformes a $45^{\circ} \mathrm{C}$ foi também verificada tanto na amostra de macarronada $\left(3 \times 10^{3} \mathrm{NMP} / \mathrm{g}\right)$ como na de carne de panela $\left(5 \times 10^{2} \mathrm{NMP} / \mathrm{g}\right)$ de dois $(8,7 \%)$ estabelecimentos (Tabela 1$)$. Em pesquisa realizada por Meldrum e colaboradores (2009), a presença de $S$. aureus e Escherichia coli foi detectada em salada de legumes o que indicou falhas nas medidas de higiene durante o preparo do alimento. Uma pequena proporção de molhos também continha Escherichia coli em 102UFC/g (3,7\%), em estudo realizado por Gilbert et al. (2000).

De acordo com os restaurantes analisados, a situação é alarmante, com a detecção de patógenos de importância epidemiológica, o que demonstra a baixa qualidade higiênico-sanitária durante o preparo dos alimentos pesquisados.

Os dois minicursos oferecidos sobre Boas Práticas de Fabricação de alimentos contaram com a participação de todos os funcionários e proprietários dos 23 estabelecimentos pesquisados e na oportunidade todos foram esclarecidos e várias dúvidas retiradas.

$\mathrm{Na}$ segunda etapa da pesquisa observou-se que as amostras coletadas de todos os 20 restaurantes avaliados estavam de acordo com a RDC 12 da ANVISA (ANVISA, 2001), apresentando uma diferença estatisticamente significante $(\mathrm{p} \leq 0,05)$ na comparação dos níveis de contaminação microbiológica dos alimentos nas duas etapas.

É necessário aos profissionais ligados à produção e processamento de produtos alimentícios, incorporarem à sua prática diária um conjunto de ações voltadas para o controle de qualidade dos alimentos (Chapman et al., 2010), desde a escolha 
da matéria-prima até a obtenção do produto final, por isto amplas ações de segurança alimentar tem sido observadas em vários países (Cates et al., 2009; Hedican et al., 2009).

Esta pesquisa vem reforçar ainda mais o conhecimento que qualquer refeição oferecida ao consumo deve estar segura sob o ponto de vista higiênico-sanitário, de forma a garantir a manutenção da saúde do consumidor. Nesta série, foi demonstrada a contaminação microbiológica excessiva dos alimentos pesquisados e por meio do aprendizado quanto aos métodos de Análise de Perigos em Pontos Críticos de Controle (APPCC) na identificação e prevenção de situações, ações ou locais que representem riscos de veiculação de doenças através dos alimentos, foi possível reverter a situação de forma significativa.

\section{Agradecimentos}

Os pesquisadores agradecem a Fundação de Amparo à Pesquisa do Estado de Goiás (FAPEG) pelo apoio financeiro concedido à pesquisa.

\section{Referências}

ANVISA - Agência Nacional de Vigilância Sanitária. 2001. Resolução RDC n⿳ 12, de 2 de janeiro de 2001. Diário Oficial da União, Brasília, 10 de janeiro de 2001. Disponível em <http://www. abic.com.br/arquivos/leg_resolucao12_01_anvisa.pdf $>$. Acesso em 16 de janeiro de 2009.

ANVISA - Agência Nacional de Vigilância Sanitária. 2002. Resolução RDC $\mathbf{n}^{\mathbf{0}} \mathbf{2 7 5}$, de 21 de outubro de 2002. Diário Oficial da União, Brasília, 23 de outubro de 2002. Disponível em <http://elegis.bvs.br/leisref/public/showAct.php?id=8134>. Acesso em 20 de janeiro de 2009.

ANVISA - Agência Nacional de Vigilância Sanitária. 2004. Resolução RDC n 216, de 15 de setembro de 2004. Diário Oficial da União, Brasília, 16 de setembro de 2004. Disponível em $<$ http:// e-legis.anvisa.gov.br/leisref/public/showAct.php?id=12546>. Acesso em 20 de janeiro de 2009.

Cates, S. C.; Muth, M. K.; Karns, S. A.; Penne, M. A.; Stone, C. N.; Harrison, J. E.; Radke, V. J. 2009. Certified kitchen managers: do they improve restaurant inspection outcomes? Journal of Food Protection, 72 (2): 384-391.
Centers for Disease Control and Prevention - CDC. 2010. Preliminary FoodNet data on the incidence of infection with pathogens transmitted commonly through food - 10 states. Morbidity and Mortality Weekly Report, 59 (14): 418-422.

Chapman, B.; Eversley, T.; Fillion, K.; Maclaurin, T.; Powell, D. 2010. Assessment of food safety practices of food service food handlers (risk assessment data): testing a communication intervention (evaluation of tools). Journal of Food Protection, 73 (6): 1101-1107.

Downes, F. P. 2001. Compedium of Methods for the Microbiological Examination of Foods. $4^{\text {th }}$ ed. Frances Pouch Downes and Keith Ito, Washington, USA, 676pp.

Gilbert, R. J.; de Louvois, J.; Donovan, T.; Little, C.; Nye, K.; Ribeiro, C. D.; Richards, J.; Roberts, D.; Bolton, F. J. 2000. Guidelines for the microbiological quality of some ready-to-eat foods sampled at the point of sale. Communicable Disease and Public Health, 3 (1): 163-167.

Havelaar, A. H.; Brul, S.; de Jong, A.; de Jonge, R.; Zwietering, M. H.; Ter Kuile, B. H. 2010. Future challenges to microbial food safety. International Journal of Food Microbiology, 30 (139 Suppl 1): S79-94.

Hedican, E.; Hooker, C.; Jenkins, T.; Medus, C.; Jawahir, S.; Leano, F.; Smith, K. 2009. Restaurant Salmonella enteritidis outbreak associated with an asymptomatic infected food worker. Journal of Food Protection, 72 (11): 2332-2336.

Jacob, C. J.; Powell, D. A. 2009. Where does foodborne illness happen-in the home, at foodservice, or elsewhere-and does it matter? Foodborne Pathogens and Disease, 6 (9): 1-5.

Kolevska, S. I.; Kocic, B. 2009. Food contamination with Salmonella species in the republic of Macedonia. Foodborne Pathogens and Disease, 6 (5): 627-630.

Lynch, M.; Painter, J.; Woodruff, R.; Braden, C. 2006. Surveillance for foodborne-disease outbreaks-United States, 1998-2002. Morbidity Mortality Weekly Report, 55 (10): 1-34.

Meldrum, R.J.; Little, C.L.; Sagoo, S.; Mithani, V.; McLauchlin, J.; de Pinna, E. 2009. Assessment of the microbiological safety of salad vegetables and sauces from kebab take-away restaurants in the United Kingdom. Food Microbiology, 26(6):573-577.

O’Brien, S. J.; Gillespie, I. A.; Sivanesan, M. A.; Elson, R.; Hughes, C.; Adak, G. K. 2006. Publication bias in foodborne outbreaks of infectious intestinal disease and its implications for evidence based food policy. England and Wales 1992-2003. Epidemiology and Infection, 134 (4): 667-674.

Pereira, M. L.; Carmo, L. S.; Lara, M. A.; Silva, S. O.; Dias, R. S.; Bergdoll, M. S. 1994. Enterotoxigenic Staphylococci from food handlers working in an industrial kitchen in Belo Horizonte-MG (Brasil). Revista de Microbiologia, 25 (3): 161-165. 